\title{
Feed-forward control of a building's heating system
}

\author{
Valery $V$. Fomin ${ }^{*}$
}

Saint Petersburg State University of Architecture and Civil Engineering, Saint Petersburg, Russian Federation

\begin{abstract}
In the heating of buildings during positive dynamics of weather conditions a problem is encountered of air temperature rise in the rooms of the building. Solution of the problem given the buildings are equipped with heating system controllers is a practical task using update algorithms in the operation of controllers. The proposed method offers an option of a heating system control algorithm to attain stable temperatures in the rooms of the building.
\end{abstract}

\section{Introduction}

Implementation of systems that automatically control heating systems offers possibilities to perfect control algorithms aimed at enhancing comfort in the rooms of the building and reducing operating expenses of consumed heat energy.

\subsection{Comfort generating factors}

\subsubsection{Control with a heat carrier}

Controllers control heat carrier consumption in accordance with outside air temperature by a temperature schedule generated by project solutions [1] and coordinated by the organization [2] supplying heat to the building. In this case the source signal for further processing comes from an outside air sensor to the controller $[3,4,5]$. Then, when the outside air parameter and the current heat carrier temperature on the supplying or returning pipeline of the heating system do not coincide, the controller sends a signal (to open or to close) to the flow controller electric drive until the heat carrier temperature is brought to comply with temperature schedule programmed in the controller. This system is able to maintain the heat carrier temperature with a sufficient accuracy, but is unable to respond to overheats [6] occurring during positive dynamics of weather conditions.

\subsubsection{Outdoor perturbing factors}

The degree of impact of outdoor perturbing factors having an effect on the excessive temperature in the rooms of the building during positive dynamics of changes in

\footnotetext{
* Corresponding author: sienef@yandex.ru
} 
weather conditions is in a wide range [7]. Firstly, it depends on the perturbing factor immediately:

- air temperature rise,

- solar activity rise,

- cessation of precipitation,

- cessation or reduction of wind speed.

Secondly, on the dynamics or nature of their changes [8].

It should also be borne in mind that in practice it is rare that only one factor has an impact; in most cases there is a combined impact of two or more factors on the enclosing structures of the heat supply facility [9]. In this case the difficulty of evaluating the impact grows greatly, and the controller provided for controlling the heat consumption of the heating system does not provide for processing outdoor information on the impact of outdoor perturbing factors and the generation of the control signal due to it being technically impossible $[3,4,5]$.

\subsubsection{Indoor perturbing factors}

The influence of indoor factors on the excessive indoor air temperature in terms of possible occurrence and amount of heat gain during the detailed familiarization with the operating conditions:

- presence/absence of people for administrative buildings [10],

- night sleep/waking of people in residential buildings [11],

- intensity of labor for manufacturing enterprises [12].

Or the heat gain characteristics due to purposes for which the buildings are designed:

- Refrigerating equipment of food stores [13],

- Heat treating furnaces used in production of industrial goods or food products [14],

- Leisure and sports centers with open water.

The determination of the heat gain, provided there is operating documentation for the equipment or technique utilized, is possible with a sufficient accuracy and implies the registration only of generation of the heat consumption balance with the assurance of the required indoor air temperatures in the rooms of the building [15].

\section{Feed-forward control method}

The offered method of controlling the heat consumption of the heating system is a control algorithm the main stages of implementation of which are:

- Generation of an individual control schedule upon various weather conditions,

- Determination of the characteristics of the building's heat storage [16],

- Parameter updating during feed-forward control of the building's heating system.

\subsection{Generation of an individual schedule}

\subsubsection{Initial parameters}

The control parameters of a building's heating system are determined on the base of the formula:

$$
Q_{o m}=\frac{G_{o m}}{1000 \cdot\left(t_{11}-t_{12}\right)}
$$

Where $Q_{o m}$ - is the heat load on the heating system, Gkal/h, $G_{o m}-$ is the consumption of the heat carrier in the heating system, tons $/ \mathrm{h}, t_{11}-$ is Temperature of the supplying heat 
carrier to the heating system, ${ }^{\circ} \mathrm{C}, t_{12}-$ is Temperature of the return heat carrier from the heating system, ${ }^{\circ} \mathrm{C}$.

When preparing the system for operation, it is necessary to implement control of consumptions through hydraulic circuits [17]. Upon completion of adjustment works in accordance with the project requirements the consumption in the system remains constant. Thus, the compensation of heat losses is affected by the temperatures of the circulating heat carrier.

\subsubsection{Algorithm of generating the individual schedule of a building's heating system}

After the adjustment the optimal result is the minimum difference between the temperatures of return pipelines in accordance with the purpose of the circuits. Fig. 1. presents the algorithm capable of generating the optimal temperature schedule of regulation of the parameters of the heat carrier under various weather conditions - factors of the outdoor perturbance of the building's heat losses. In the archiving process the arrays of parameters are created corresponding to the full spectrum of combined impact of outdoor factors on the temperature conditions of the building. As a building is a complex facility affected by indoor and outdoor perturbing factors, the controlling signal may be adjusted (if differences occur when comparing to similar parameters) as implemented in block 4 and based on the analysis of the air temperatures in the rooms.

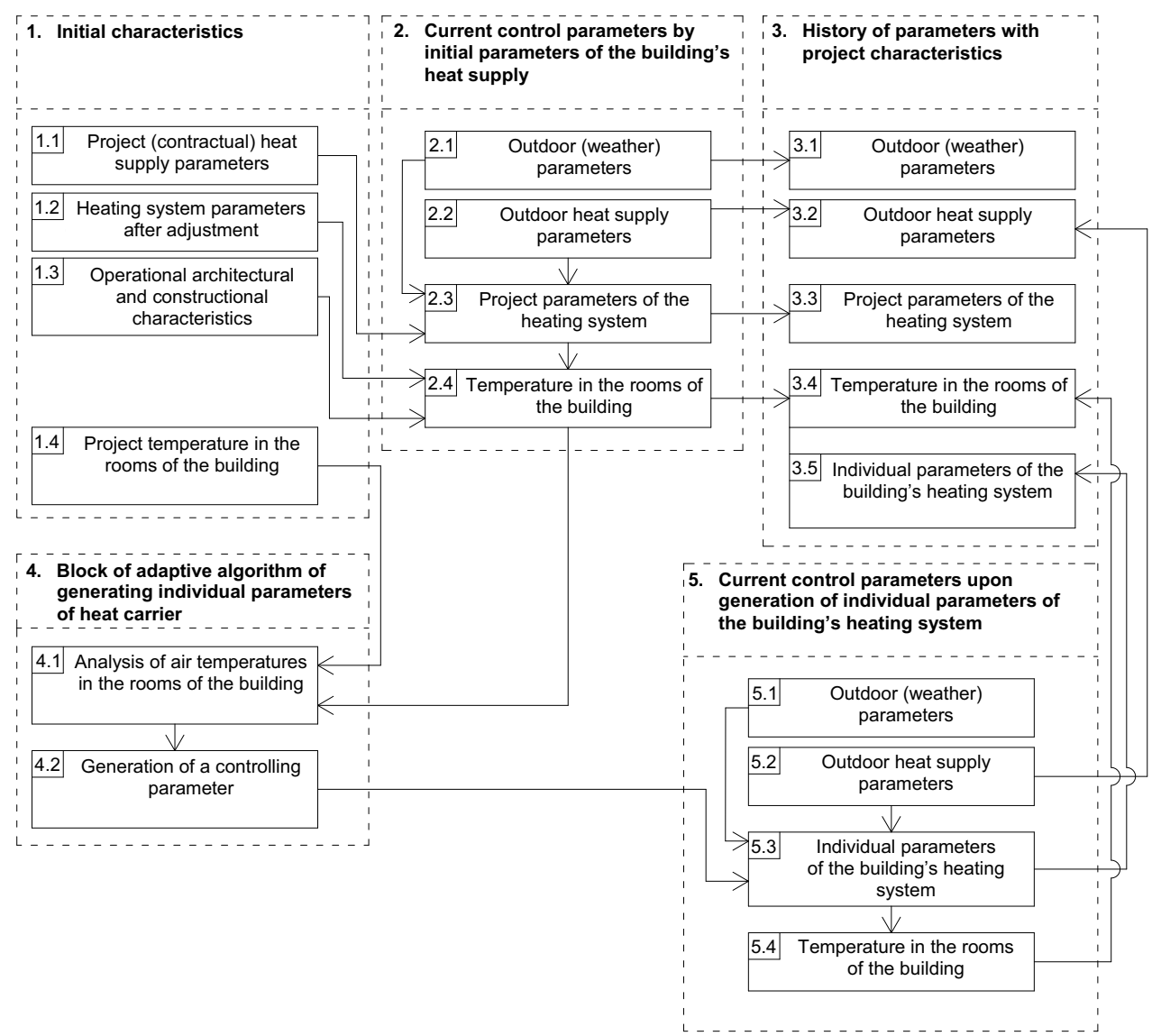

Fig. 1. Algorithm of generating the individual parameters of the building's heating. 


\subsection{Determination of parameters of a building's heat storage}

To implement the feed-forward control method by a heating system, the essential criterion for its implementation is the determination of the parameters of the building's heat storage.

\subsubsection{Prerequisites and conditions of determination of a building's heat storage}

When developing the project documentation for a building an important section is determination of the composition and quantity of the material of the enclosing structures of the building. In the result of calculations for compliance with the current energy efficiency standards one can determine the building's design heat storage capacity. In the process of construction and operation of the building the thermotechnical parameters may worsen from the controlled norms, namely:

- Non-compliance with the technology during construction of the building,

- Natural deterioration of the characteristics, utilized materials in the operation of the building,

- Enhancement of the requirements to the building's energy efficiency.

Thus, it is necessary to periodically compare the building's heat characteristics with a view to their retention or possible improvement.

When determining the parameters of a building's heat storage, it is necessary to meet the conditions conducive to the determination of the most accurate values. Such conditions include the stability of indoor and outdoor perturbing factors [18]. The practical assurance of these conditions in the process of operation is difficult and takes a lengthy period.

\subsubsection{Algorithm of determining a building's heat storage}

The practical determination of the heat storage parameters should be carried out only after generation of the temperature schedule in the maximum possible range of weather conditions. The maximum number of separate or combined factors of outdoor perturbance will be conducive to the accurate values when generating the parameters of the building's heat storage.

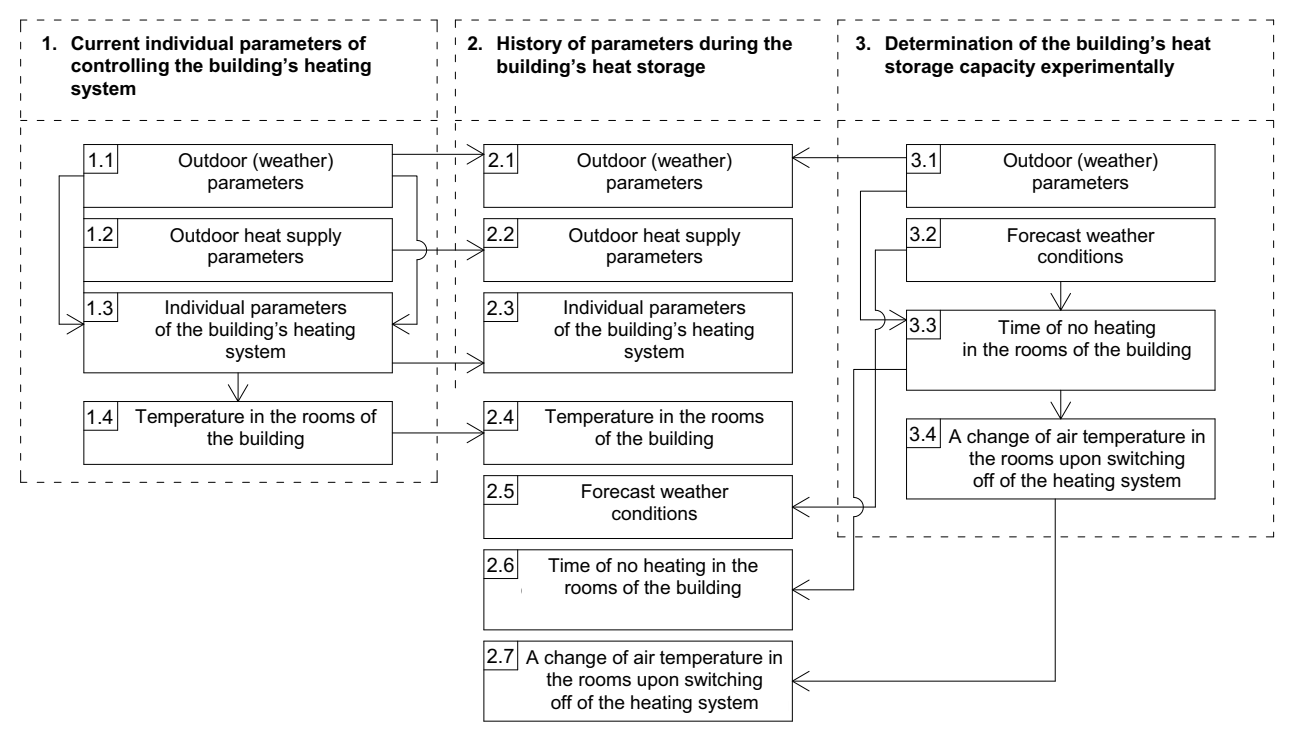

Fig. 2. Algorithm of generating the parameters of the building's heat storage. 
To make it possible to use the heat storage in feed-forward control, one of the main parameters is the time of change in the indoor air temperature for a period [19]:

$$
d z=\frac{F \cdot s \cdot \rho \cdot c}{2 \cdot q_{o} \cdot V} \frac{d t_{B}}{t_{B}-t_{H}-\frac{Q_{o m}}{q_{o m} \cdot V}}
$$

where $d z$ - is heat load on the heating system, $\frac{F \cdot s \cdot \rho \cdot c}{2 \cdot q_{o} \cdot V}=\beta$ is the ratio of the building's heat storage, $\mathrm{h}, d t_{b}$ of temperatures of the return heat carrier from the heating system, $t_{b}$ of temperatures of the return heat carrier from the heating system, $t_{H}$ of temperatures of the return heat carrier from the heating system, $Q_{o m}$ of temperatures of the return heat carrier from the heating system, $q_{o m}$ of temperatures of the return heat carrier from the heating system, $V$ of temperatures of the return heat carrier from the heating system.

As a result of development of the history of parameters registering the change in the indoor air temperatures in the rooms of the building depending on the variety of weather conditions an opportunity appears to change the control system.

\subsection{Feed-forward control of heat consumption for the heating system by forecast weather conditions}

After having determined the properties characterizing the ability of the building to retain heat energy, an opportunity appears to use them in practical control when operating the facility in the heating season.

\subsubsection{Opportunities when using the building's heat storage.}

The use of the heat storage properties of the building is applicable to a situation conducive to the reduction of the heat losses of the building. Conditionally, they can be divided into three groups:

- A daytime temperature rise. Especially characteristic in a transitional (spring, fall) period of the heating season with a noticeable impact of the solar radiation [20],

- An anticyclone period with an outdoor air temperature rise prolonged in time and considerable in amount,

- Positive dynamics in a change in wind force or cessation of atmospheric precipitation. It is also necessary to note that an important criterion of using feed-forward in control is the analysis of forecast and credibility of a short-term forecast [21].

\subsubsection{Feed-forward control algorithm with the use of the properties of the building's heat storage determined under practical conditions}

After determining the thermotechnical properties of the building's behavior under various weather conditions one can go to the feed-forward control algorithm based on the weather forecast data. 


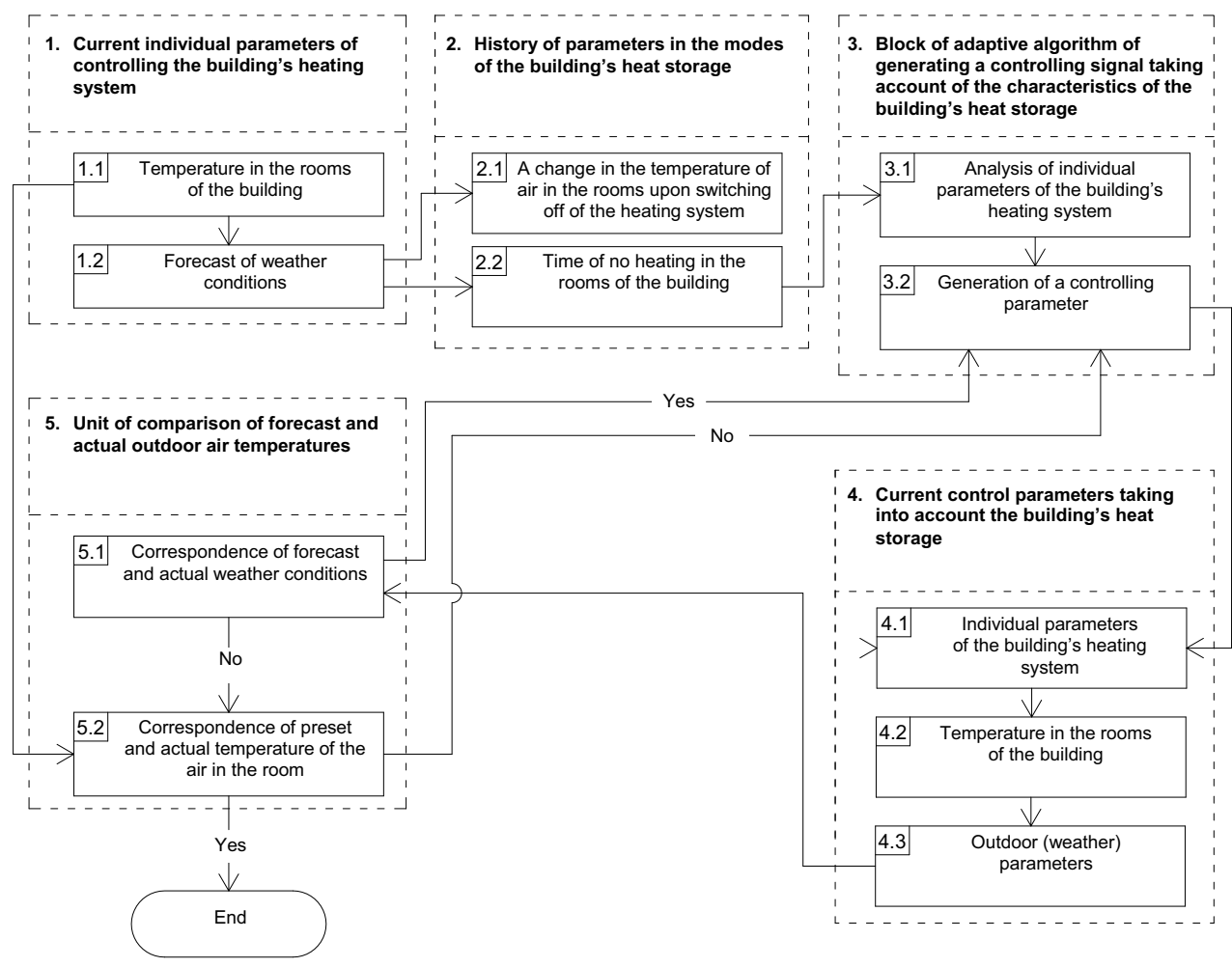

Fig. 3. Feed-forward control algorithm by forecast of weather conditions.

The algorithm presented in Fig. 3 is a cyclicity in the generation of the indoor air temperature until the preset range of temperatures in the building is attained. The end result of using the weather forecast in the control of the heating system must be the stability of the air temperature in the rooms of the building during the positive dynamics of changes in weather conditions.

\section{Conclusion}

The practical implementation of the feed-forward control algorithm is referred to adaptive problems enhancing comfort in the rooms and the economic benefit of using a heat carrier in heating of buildings. The end result of using the weather forecast in the control of a heating system should be the stability of air temperature in the rooms of the building during the positive dynamics of changes in weather conditions.

\section{References}

1. Federal Act Urban Planning Code of the Russian Federation dated 29.12.2004 No.190-Ф3 (2004)

2. Federal Act On Heat Supply dated 27.07.2010 No.190-Ф3 (2010)

3. Manual of the controllers ECL made by Danfoss

4. Manual of the controllers RVP made by Siemens 
5. Manual of the controllers MVC80 made by Honeywell

6. V.N. Bogoslovsky, Construction Thermophysics (Higher School, Moscow, 2006)

7. N.V. Kobysheva, A Study of Climatic Activity in Saint Petersburg, a collection Quality of Urban Heat Supply, 110

8. S.P. Khromov, M.A. Petrosyants, Meteorology and Climatology (MSU, Moscow, 2001)

9. Yu.Ya. Kuvshinov, Theoretical Principles of Assuring the Indoor Climate of a Room, (ACB, Moscow, 2007)

10. V.V. Zelikov, Handbook of an Engineer in Heating, Ventilation, and Air Conditioning (Infra-Ingeneriya, 2011)

11. A. Machkashi, L. Bankhidi, Radiant Heating (1985)

12. B.S. Molchanov, Design of Industrial Ventilation (Stroyizdat, Leningrad, 1970)

13. N.D. Kochetkov, Refrigerating Engineering in Eating and Shopping Facilities (Gos.Izd. torgovoi literatury, 1955)

14. V.S. Kedrov, Yu.V. Kedrov, V.A. Chukhin Swimming Pools (Stroyizdat, Moscow, 2002)

15. V.N. Lavrenchik, A Set-up of a Physical Experiment and Statistical Processing of its Results (Energoizmat, Moscow, 1986)

16. Ye.Ya. Sokolov, District Heating Cogeneration and Heating Networks (MEI, Moscow, 1999)

17. I.M. Sorokin, A.I. Kuznetsov, L.M. Aleksandrov, L.A. Rogov, Setup of District Heating Systems (Stroyizdat, Moscow, 1979)

18. V. A. Pukhkal, Modern Problems of Science and Education, 5 (2014)

19. T. G. Manukovskaya, V.A. Sterligov, Issues of Modern Science and Practice, 3 (2011)

20. V.I. Vissarionov, G.V. Deryugina, V.A. Kuznetsova, N.K.Malinin, Solar Energy (MEI, Moscow, 2008)

21. L.S. Gandin, A.S. Dubov, Numerical Methods of Short-Time Weather Forecast (Gidrometeoizdat, Leningrad, 1968) 